\title{
FRAGILITY ANALYSIS OF OPEN GROUND STOREY RC BUILDING DESIGNED USING VARIOUS MULTIPLICATION FACTORS
}

\author{
D. J. Chaudhari ${ }^{1}$, Prajakta T. Raipure ${ }^{2}$ \\ ${ }^{1}$ Professor, Applied Mechanics Department, Government College of Engineering, Amravati, Maharashtra, India \\ ${ }^{2} P G$ Student, Applied Mechanics Department, Government College of Engineering, Amravati, Maharashtra, India
}

\begin{abstract}
The vulnerability of an element is defined as the probability that the said element will sustain a specified degree of structural damage given a certain level of ground motion severity. Significantly low stiffness and strength in any storeys compared to adjacent storeys is generally referred to as soft ground storey. As the columns of this Open ground storey are weakest element, ground storey is most vulnerable. Open ground storey framed buildings are generally analyzed in practice ignoring infill wall stiffness (linear bare frame analysis). Design codes impose a multiplication factor on the design forces in the columns of ground storey. The present study attempts to estimate and compare performance of open ground storey building designed with three different multiplication factors given by Indian code and Israel code. Thus fragility curves are derived using nonlinear dynamic time history analysis carried on a $(G+9)$ OGS building by using method suggested by Cornell. Probabilistic seismic demand models are developed by using power law model. Results show that performance of upper storeys while applying multiplication factor only to the ground storey needs to be checked. The first storey is more vulnerable than the ground storey except for Israel code.
\end{abstract}

Keywords: Open ground storey, multiplication factors, fragility, performance levels, PSDM Model

\section{INTRODUCTION}

In performing a seismic risk analysis of a structural system, it is essential to identify seismic vulnerability of component structures associated with various states of damage. The development of vulnerability information in the form of fragility curves is a widely practiced approach. Fragility functions are the essential tools for seismic loss estimation. They represent the probability of attaining or exceeding a damage limit state for a given structure type subjected to a seismic excitation (Shinozuka et al. 1999). Fragility curves are the conditional probability of exceedance of response of a structure for a given ground motion severity. Fragility curves are used commonly for the estimation of probability of damage of structure due to earthquakes as a function of ground motion indices or other design parameters.

\subsection{Open Ground Storey}

Due to increasing population from the last few years car parking space for residential apartments in populated cities is a matter of major concern. Hence the trend has been to utilize the ground storey of the building for parking. These types of buildings (Fig.1) having no infill masonry walls in ground storey, but infilled in all upper storeys, are called Soft stories buildings. They are also known as 'open ground storey building. From functional point of view, these buildings are significantly advantageous but from a seismic performance point of view such buildings are considered to have increased vulnerability.

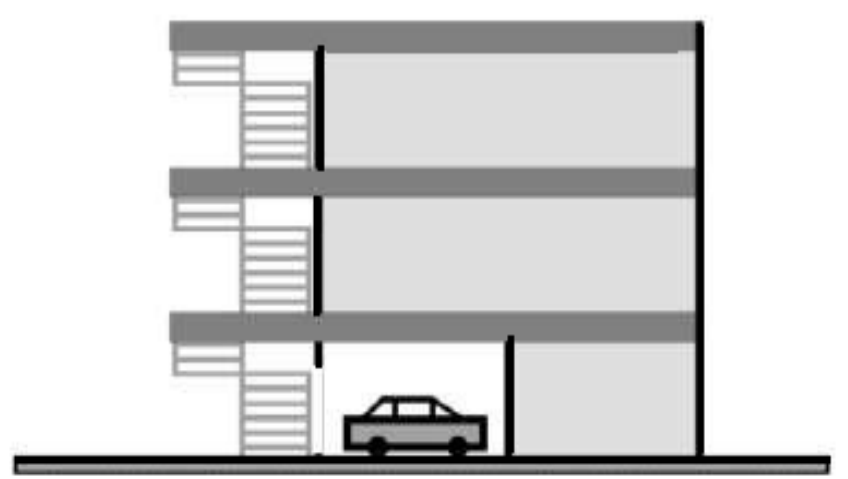

Fig-1: Soft storey for parking space

From the past earthquakes it was evident that the major type of failure that occurred in soft story buildings included snapping of lateral ties, buckling of longitudinal reinforcement bars, crushing of core concrete etc. Due to the presence of infill walls in the entire upper storey except in the ground storey makes the upper storeys much stiffer than the open ground storey. Thus, the upper storeys move almost together as a single block, and most of the horizontal displacement of the building occurs in the soft ground storey itself. In other words, this type of buildings sway back and forth like inverted pendulum during earthquake shaking, and hence the ground storey columns and beams are heavily stressed. Therefore it is required that the ground storey columns must have sufficient strength, stiffness and adequate ductility. The vulnerability of this type of building is attributed to the sudden lowering of lateral stiffness and strength in open ground storey, compared to upper storeys with infill walls. 
In the aftermath of the Bhuj earthquake, the IS 1893 code was revised in 2002, incorporating new design recommendations to address soft story buildings. Clause 7.10.3(a) states: The columns and beams of the soft storey are to be designed for 2.5 times the storey shears and moments calculated under seismic loads of bare frames. The factor 2.5 can be told as a multiplication factor (MF) or Magnification factor. This multiplication factor (MF) is supposed to be the compensation for the stiffness discontinuity. Other national codes also recommend different multiplication factors for this type of buildings of which Israel code is being considered here. Israel code allows soft or weak storey, including open ground storey, only in buildings with low or medium ductility levels. The design forces for flexible or weak storey members, and for the members in the storey above and below, are required to be increased by a factor $0.6 \mathrm{R}$, where $\mathrm{R}$ is the response reduction factor. For masonry infilled $\mathrm{RC}$ frame buildings, $\mathrm{R}$ is 3.5 for low ductility level, and 5.0 for medium ductility level. Therefore, the beams and columns of the soft/weak storey, and also the adjacent stories are required to be designed for at least 2.1-3.0 times the design forces for regular storey, depending upon the level of ductility. Here considering the low ductility level the building is designed by using multiplication factor of 2.1 .

The main objective of this study is To study and compare the seismic performance of typical OGS buildings designed as per applicable provisions in international codes in a Probabilistic framework and to make use of probabilistic seismic demand model to derive fragility curves.

\section{DEVELOPMENT OF FRAGILITY CURVES}

The fragility can be expressed in closed form using following equation,

$$
P(C-D \leq 0 / I M)=\emptyset\left(\frac{\ln \frac{S_{d}}{S_{c}}}{\sqrt{\beta_{d / I M}^{2}+\beta_{c}^{2}}}\right)
$$

Where, $C$ is the drift capacity, $D$ is the drift demand, $S d$ is the median of the demand and $S c$ is the median of the chosen damage state $(D S) . \beta \mathrm{d} / \mathrm{IM}$ and $\beta \mathrm{c}$ are dispersion in the intensity measure and capacities respectively. Above Eq. can be rewritten as Eq. for component fragilities (Nielson, 2005) as

$$
P(D S / I M)=\emptyset\left(\frac{\ln I M-\ln I M_{m}}{\beta_{c o m p}}\right)
$$

Where $I M_{M}=\exp \left(\frac{\ln s_{c}-\ln \alpha}{b}\right), a$ and $b$ are the regression coefficients of the probabilistic Seismic Demand Model (PSDM) and the dispersion component,
$\beta_{D / M}$ is given as

$$
\beta_{D / M}=\sqrt{\frac{\Sigma\left(\ln \left(d_{i}\right)-\ln \left(a I M^{b}\right)\right)^{2}}{N-2}}
$$

$B_{\text {comp }}$ is given as,

$$
\beta_{\text {comp }}=\sqrt{\frac{\beta_{d / I M}^{2}+\ln I M_{m}}{b}}
$$

The dispersion in capacity, $\beta \mathrm{c}$ is dependent on the building type and construction quality. For $\beta \mathrm{c}$, ATC 58 50\% draft suggests $0.10,0.25$ and 0.40 depending on the quality of construction. In this study, dispersion in capacity has been assumed as 0.25 .

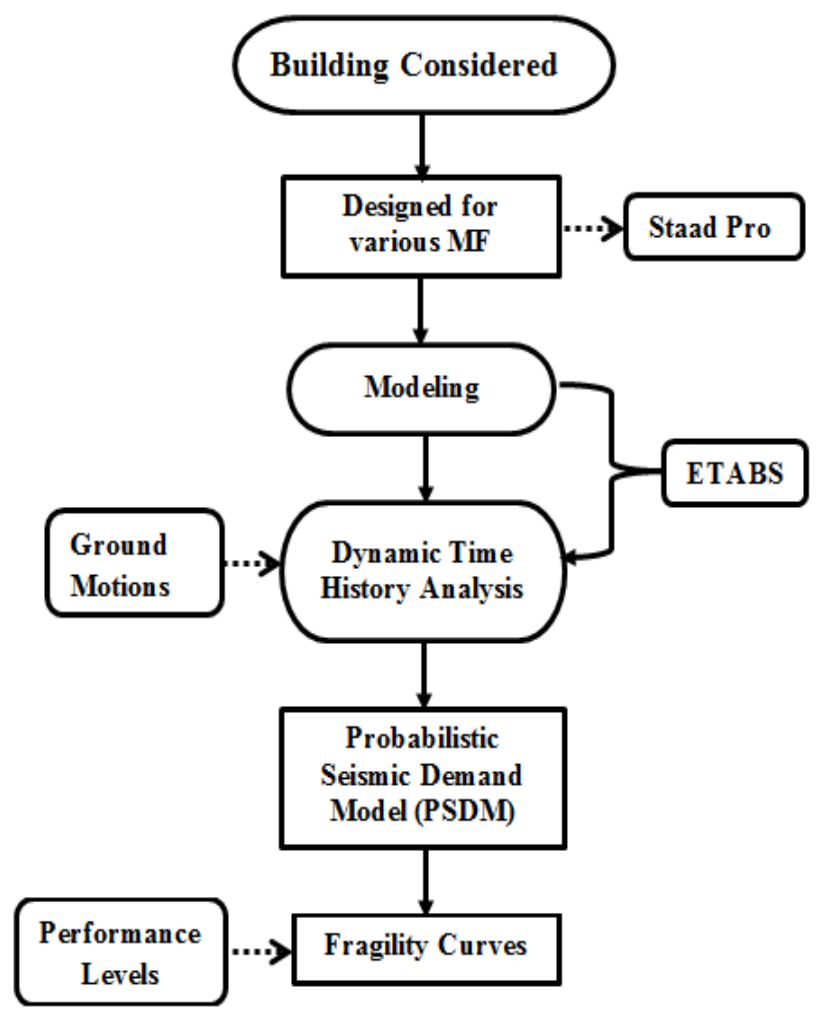

Fig-2: Flowchart for Development Of Fragility Curves

\section{MODELLING}

\subsection{Details of Buildings Considered}

A ten-storey six-bay OGS RC frame that represents a symmetric building in plan is considered. Concrete and steel grades are taken as M25 and Fe415 respectively. Bay width and column height are taken as $3 \mathrm{~m}$ and $3.2 \mathrm{~m}$ respectively. Slab thickness is of $150 \mathrm{~mm}$. A live load of $3 \mathrm{KN} / \mathrm{m}^{2}$ is considered at all floor levels except top floor, where it is considered as $1.5 \mathrm{KN} / \mathrm{m}^{2}$. Seismic load is taken according to IS 1893 (2002). The building considered is located in seismic zone $\mathrm{V}$ having $\mathrm{Z}=0.36$ with medium soil and $\mathrm{R}$ value considered as 3 for ordinary $\mathrm{RC}$ moment resisting frame 
(OMRF). The building is assumed to be symmetric in both orthogonal directions in plan. The torsional response is neglected. Parapet wall of $0.6 \mathrm{~m}$ is considered. The columns and beams considered are of sizes $450 \mathrm{~mm} \times 450 \mathrm{~mm}$ and $230 \mathrm{~mm} \times 350 \mathrm{~mm}$ respectively. As the building is an OGS frame, the ground storey columns are to be designed taking into account of the Multiplication Factor for Indian and Israel code as considered.
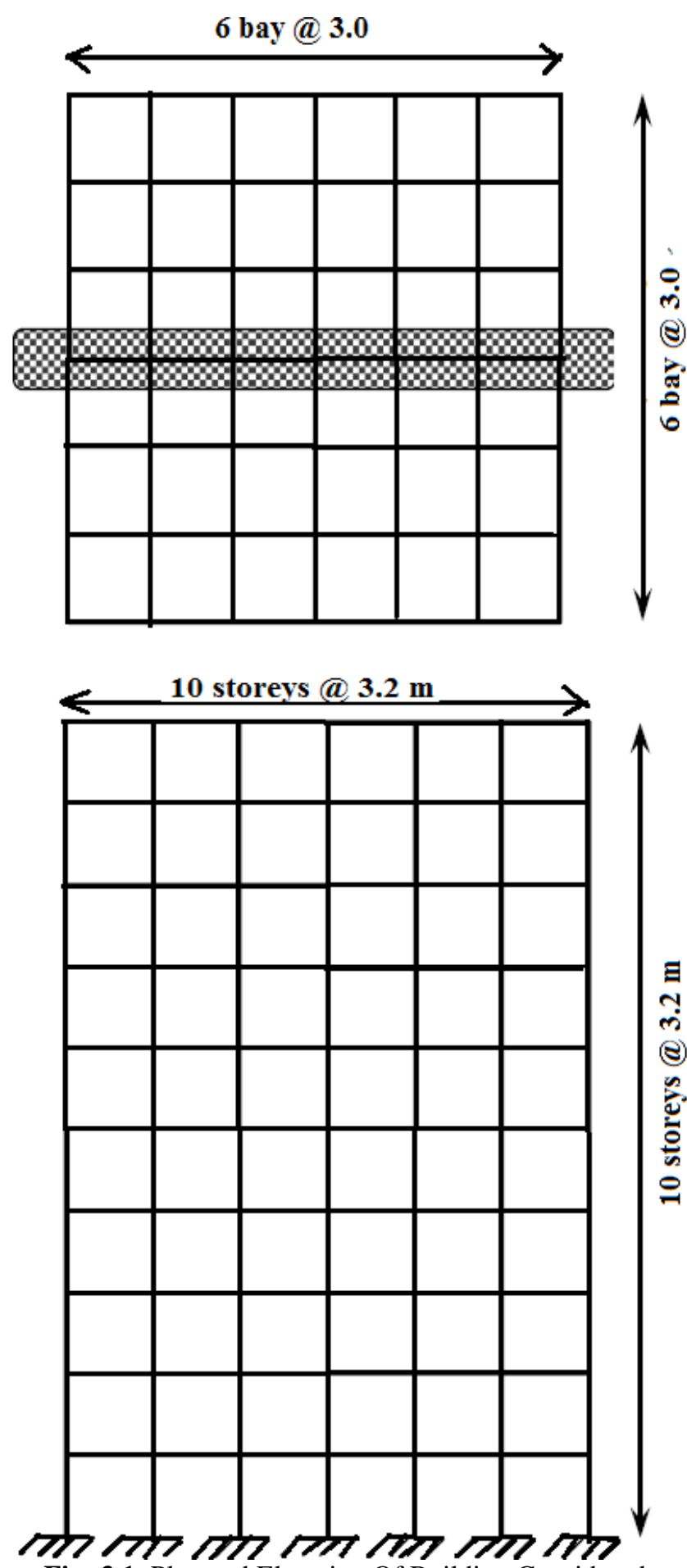

Fig- 3.1: Plan and Elevation Of Building Considered

Analysis and design by using IS 1893:2002 Part 1, and 456:2000 is carried out in the software STAAD PRO.
Table-3.1: Design Details Of The Example Building Considered

\begin{tabular}{|l|l|l|}
\hline Frame designation & $\begin{array}{l}\text { Ground storey } \\
\text { column section }\end{array}$ & $\begin{array}{l}\% \text { Reinf. } \\
\text { Provided }\end{array}$ \\
\hline $\begin{array}{l}10 \text { storey 6 bay, } \\
\text { OGS }(\mathrm{MF}=1)\end{array}$ & $450 \times 450$ & 3.93 \\
\hline $\begin{array}{l}10 \text { storey 6 bay, } \\
\text { OGS }(\mathrm{MF}=2.5)\end{array}$ & $750 \times 750$ & 3.57 \\
\hline $\begin{array}{l}10 \text { storey 6 bay, } \\
\text { OGS }(\mathrm{MF}=2.1)\end{array}$ & $650 \times 650$ & 3.8 \\
\hline
\end{tabular}

\subsection{Nonlinear Dynamic Analysis}

Twenty different time histories including some of the Indian time histories are used to carry out nonlinear dynamic analysis to capture the maximum inter-storey drift at ground $1^{\text {st }}$ and $2^{\text {nd }}$ storey. Each Building frames are modeled in the ETABS Software (Version 9.7.3) which is a finite element program.

\section{RESULTS AND DISCUSSIONS}

\subsection{Probabilistic Seismic Demand Model (PSDM)}

It has been suggested by Cornell (2002) that the median engineering demand parameter $(E D P)$ can be estimated by using power law model which is given by equation,

$$
\mathrm{EDP}=\mathrm{a} \mathrm{IM}^{\mathrm{b}}
$$

In this present study, inter-storey drift $(\delta)$ at the first floor level i.e. ground storey drift is taken as the engineering damage parameter $(E D P)$ and peak ground acceleration $(P G A)$ as the intensity measure (IM).

The nonlinear dynamic analyses are used to build the PSDM. Nonlinear time history analyses of all the twenty models have been performed to obtain a set of twenty interstorey drifts for the corresponding PGAs. The parameters ' $a$ ' and ' $b$ ' of the equation are determined for the set of twenty values by performing a regression analysis using power-law. The demand models for buildings considered are obtained using linear regression analysis. The parameters ' $a$ ' and ' $b$ ' of PSDM models of all the frames are shown in the Table 4.2.1.1. The inter-storey drift at the ground storey is more for the OGS 1.0 and the inter-storey drift also reduces as the MF increases. 


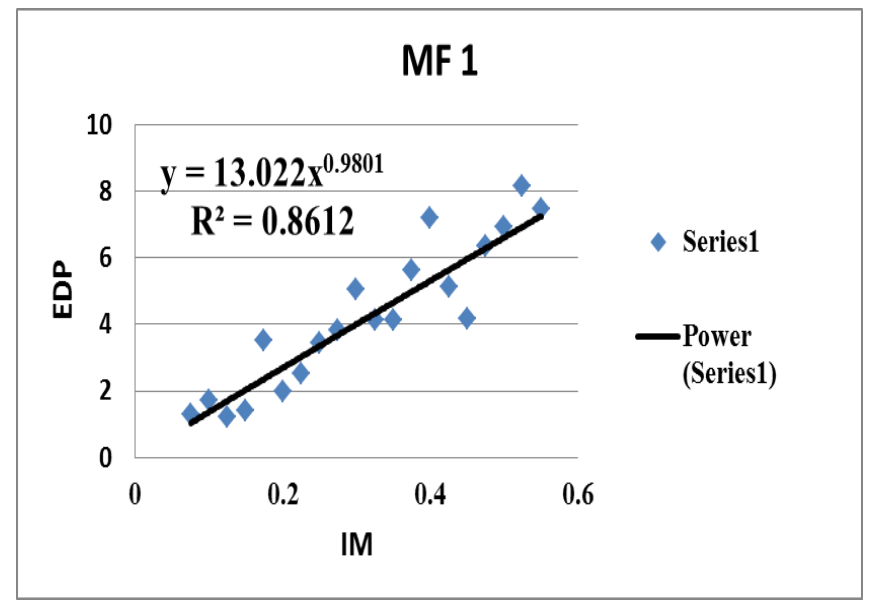

Fig-4.1: PSDM Model for OGS (Indian 1)

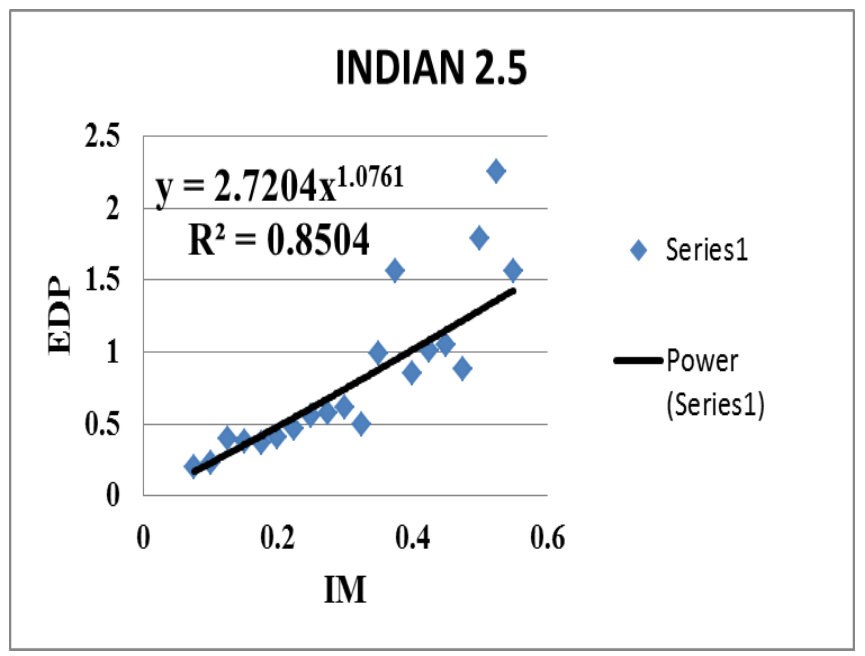

Fig- 4.2: PSDM Model for OGS (Indian 2.5)

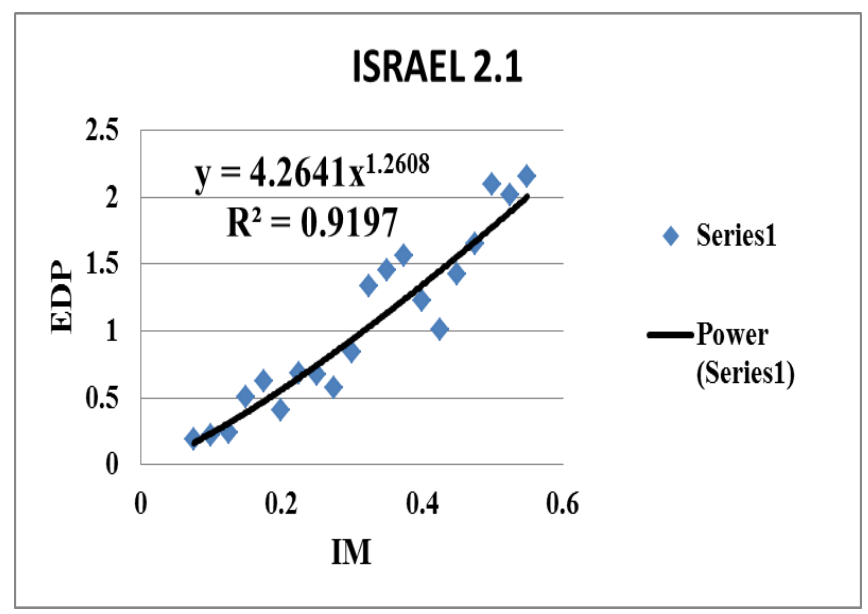

Fig- 4.3: PSDM Model for OGS (Israel 2.1)

Table 4.1: Parameters of Probabilistic Seismic Demand Model (PSDM)

\begin{tabular}{|l|l|l|}
\hline Name of building & $\mathbf{a}$ & $\mathbf{b}$ \\
\hline MF 1 & 13.022 & 0.9801 \\
\hline Indian 2.5 & 2.7204 & 1.0761 \\
\hline Israel & 4.2641 & 1.2608 \\
\hline
\end{tabular}

\subsection{Building Performance Levels}

Building performance can be described qualitatively in terms of the

- Safety experienced by the building occupants, during and after an earthquake.

- Cost and feasibility of restoring the building to preearthquake conditions.

- Length of time required when the building is removed from service to conduct repairs.

- Economic, architectural, or historic impacts on the community at large.

These performance levels will be directly related to the extent of damage sustained by the building during a damaging earthquake.

Table-4.2: Damage Limits With Various Structural Performance Levels for RC Frames

\begin{tabular}{|l|l|l|}
\hline $\begin{array}{l}\text { Limit state } \\
\text { designation }\end{array}$ & Performance level & $\begin{array}{l}\text { Inter storey } \\
\text { Drifts, } \mathbf{S}_{\mathbf{c}}(\mathbf{\%})\end{array}$ \\
\hline $\begin{array}{l}\text { Immediate } \\
\text { occupancy(IO) }\end{array}$ & $\begin{array}{l}\text { Light repairable } \\
\text { damage }\end{array}$ & 1 \\
\hline Life safety(LS) & $\begin{array}{l}\text { Moderate repairable } \\
\text { damage }\end{array}$ & 2 \\
\hline $\begin{array}{l}\text { Collapse } \\
\text { prevention(CP) }\end{array}$ & Near collapse & 4 \\
\hline
\end{tabular}

\subsection{Comparison of Fragility Curves}

The application of multiplication factors to ground storey columns only increases its strength and stiffness. It is observed from Figure. 4.4 that the OGS frame designed with $\mathrm{MF}=1.0$ is about $80 \%$ fragile for IO level, about $15-20 \%$ fragile for LS level and close to $0 \%$ for CP level. Ground storey columns have been multiplied by 2.5 times of B.M and S.F of bare frame thus increasing the ground storey columns sections. It can be seen that the performance of the building (probability of exceedance of inter-storey drift) is increased when compared to the building designed with MF $=1$. The probability of exceedance is near about zero for all the three performance levels IO, LS and CP for building designed with MF 2.5.

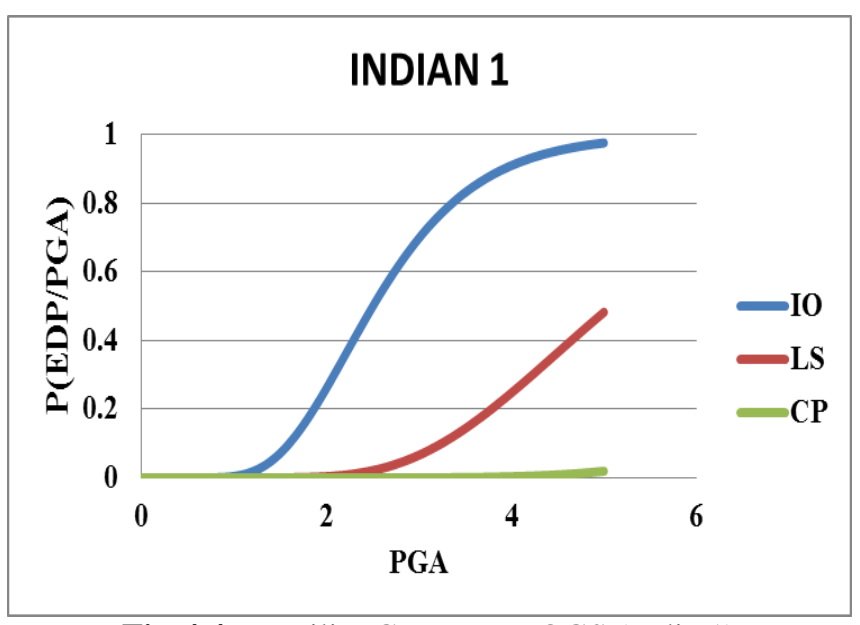

Fig-4.4: Fragility Curves For OGS (India 1) 


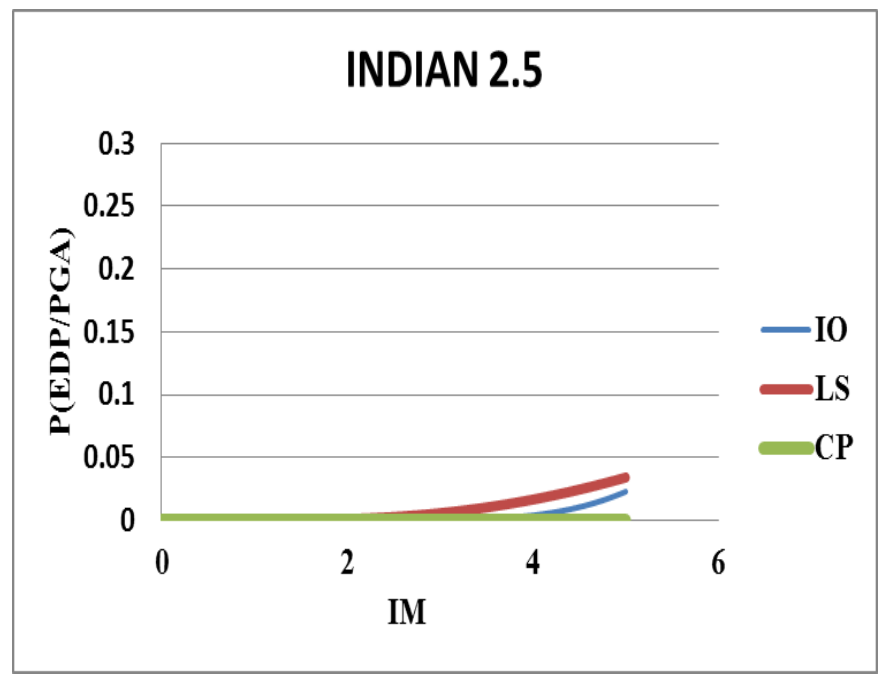

Fig-4.5: Fragility Curves for OGS (India 2.5)

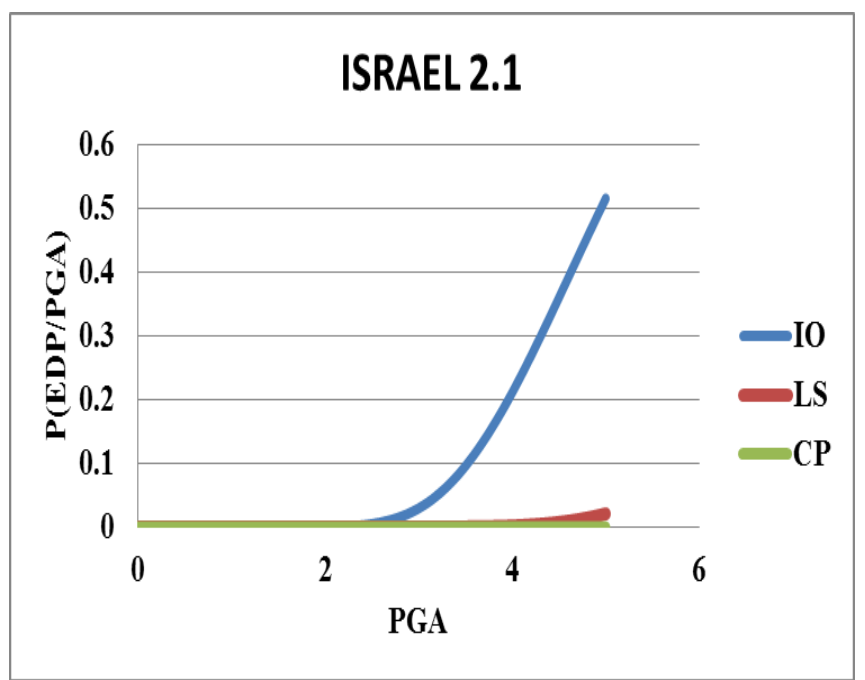

Fig-4.6: Fragility Curves for OGS (Israel 2.1)

\subsubsection{Comparison of Fragility Curves at Various} Storeys for IO level

It is required to study the performance of storeys other than ground storey, thus the exceedance probability of interstorey drift for the other storeys for IO performance level are developed. Figure 4.7 shows the fragility curves for the OGS frame designed for MF $=1.0$ for different storeys. It is observed that the first storey is more vulnerable than the upper storeys.

Figure 4.8 shows the storey wise exceedance probability of the building designed using multiplication factor, 2.5 as per Indian code. It is seen that the first storey is more vulnerable than the second and ground storeys. This implies that performance of the above storeys also needs to be checked while using multiplication factors. Indian Code applies Multiplication factors only in the ground storey but Israel code applies a factor of 2.1 for both ground and first storey which reduces the exceedance probability considerably (Figure 4.9) and uniformly in all storeys, compared other codes.

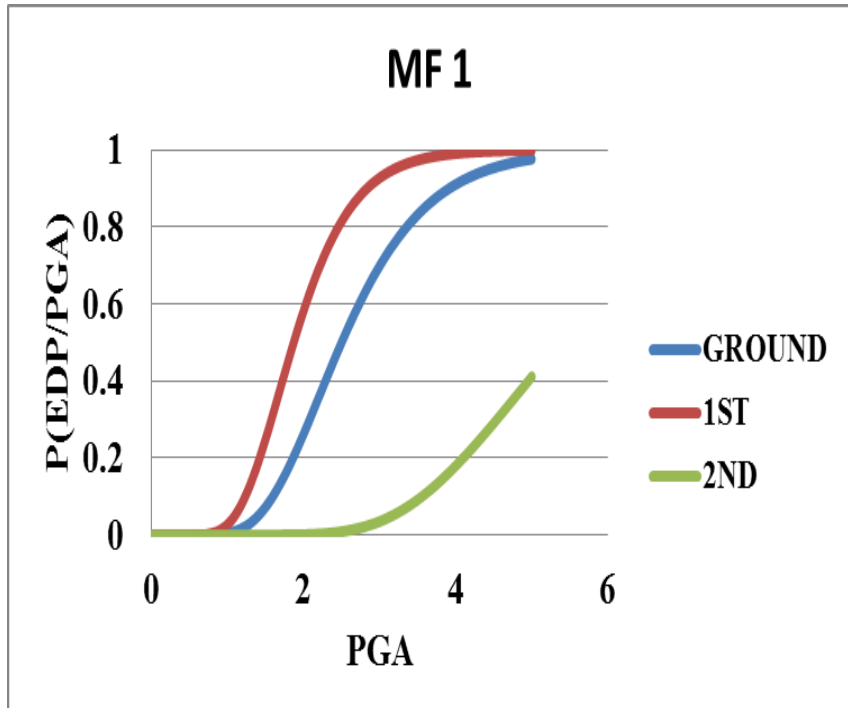

Fig-4.7: Fragility Curves for Ground, $1^{\text {st }}$ And $2^{\text {nd }}$ Storey Designed By Using MF 1

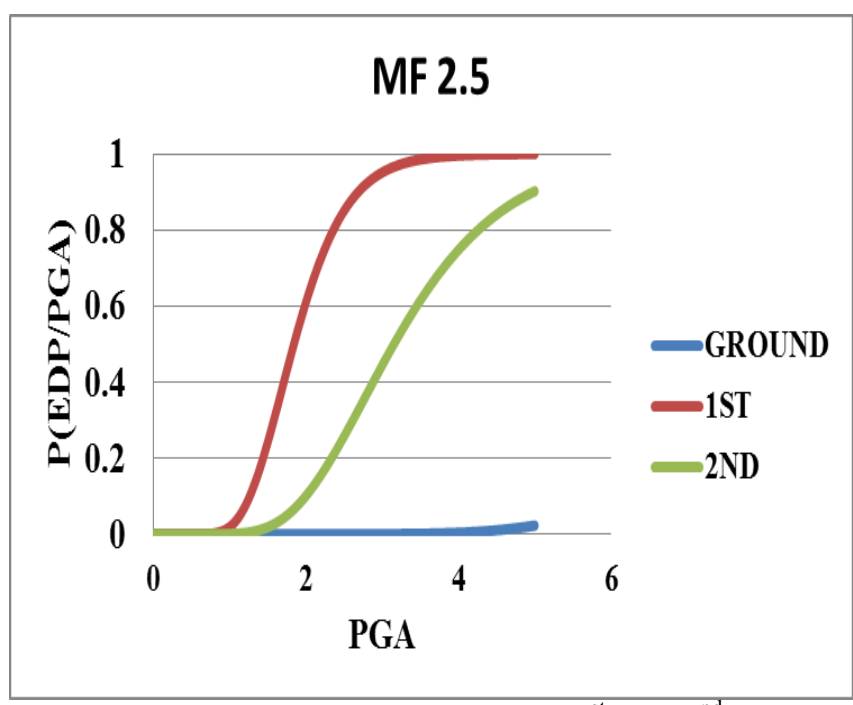

Fig-4.8: Fragility Curves for Ground, $1^{\text {st }}$ And $2^{\text {nd }}$ Storey Designed By Using MF 2.5

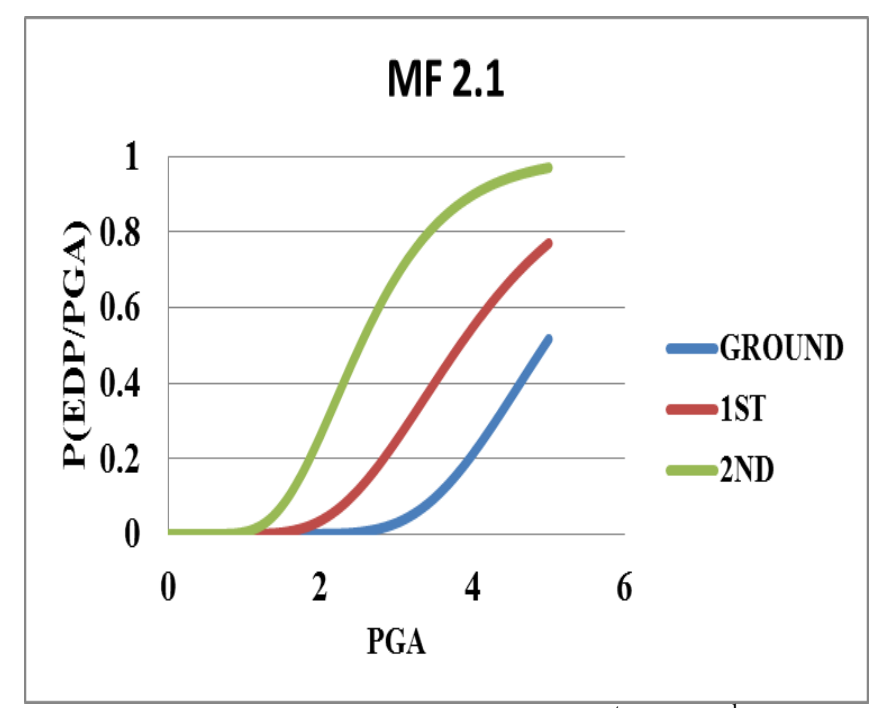

Fig-4.9: Fragility Curves for Ground, $1^{\text {st }}$ And $2^{\text {nd }}$ Storey Designed By Using MF 2.1 


\subsubsection{Comparison of Fragility Curve For Each Storeys For IO Level}

A Comparison of fragility curve for each storey for different codes is made to understand the behavior of stories other than ground storey. Figure 4.10 represents the fragility curve of ground storey for various codes. As the Israel code uses the MF factor of 2.1, the resulting fragility is more at ground storey compared to that of other codes.

Figure 4.11 represents the fragility curve of first storey which shows that the probability of exceedance of interstorey drift is decreased for Israel code as the Indian code does not consider multiplication factor to the first storey whereas Israel code takes it into consideration. In other words, the first storey of all the frames designed by codes other than Israel code remains same to yield same exceedance probability.

Figure 4.12 represents the fragility curves for second storey of all the three frames considered. It can be seen that the fragility of the second storey is slightly higher for Israel code.

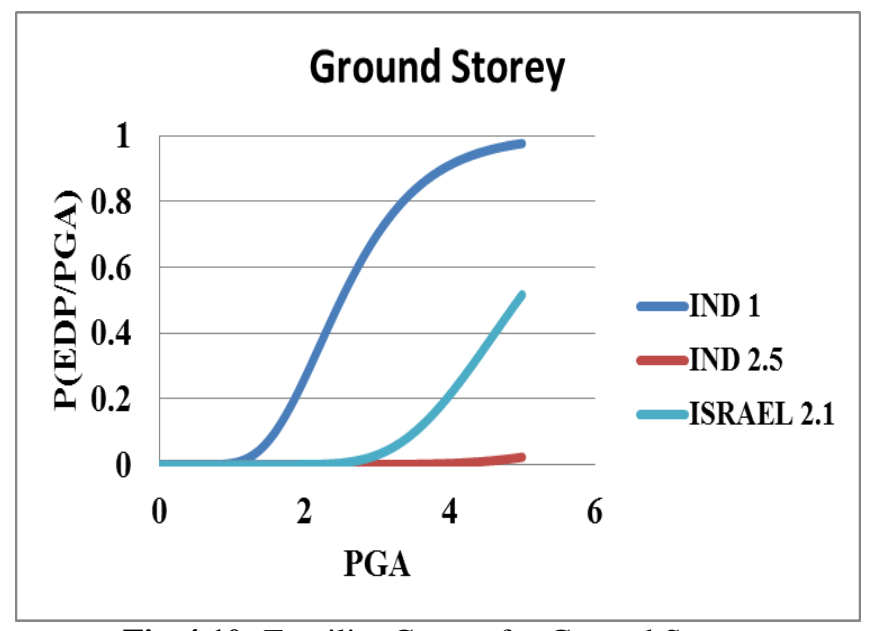

Fig-4.10: Fragility Curves for Ground Storey

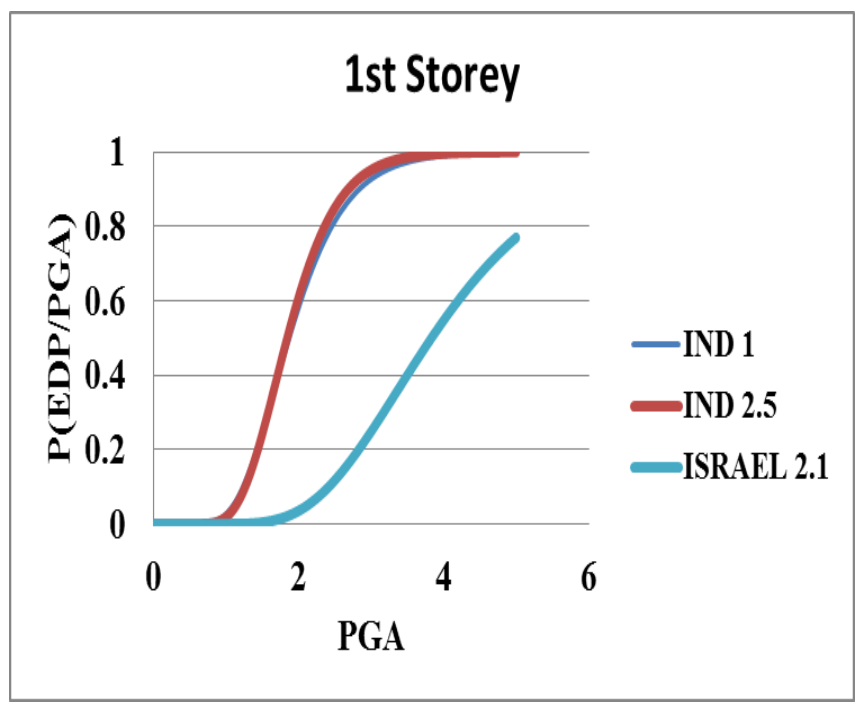

Fig-4.11: Fragility Curves for First Storey

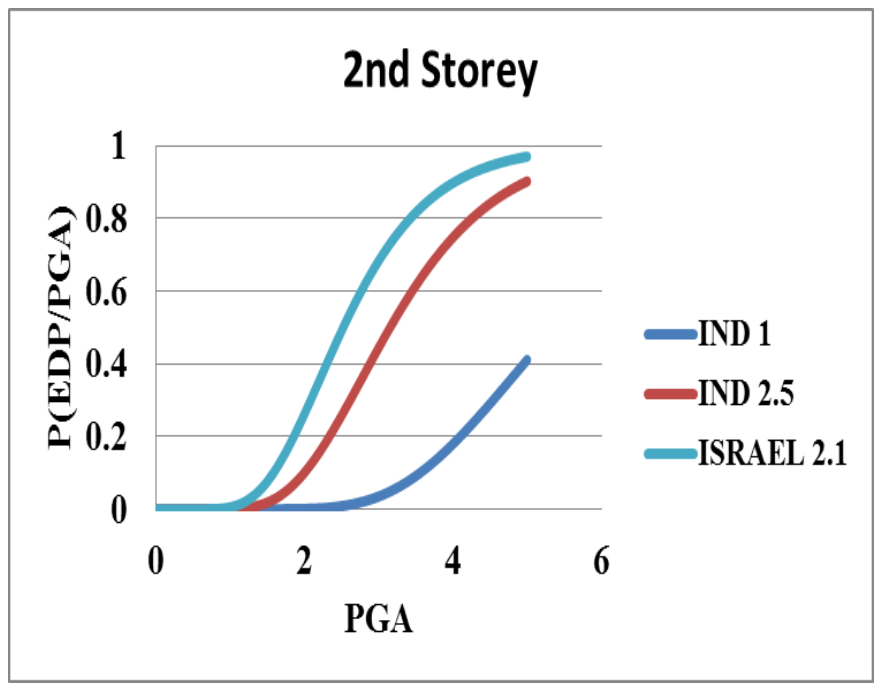

Fig-4.2: Fragility Curves for Second Storey

\section{CONCLUSION}

Based on the above research works, following conclusions are obtained:

1. It is found that the performances of the OGS frames, in terms of ground storey drift is increasing in the increasing order of magnification factors used by Indian and Israel code for all the performance levels.

2. In case of Indian code first storey is more vulnerable than the ground storey whereas for Israel code it is not so.

3. It is found that relative vulnerability of first storey increases due to strengthening of the ground storey.

4. Application of magnification factor only in the ground storey may not provide the required performance in all the other stories. It is found from the study that the OGS buildings designed using Israel code, which considered the magnification factor in the adjacent storey, performed better compared to Indian. This indicates that the application of multiplication factor in the adjacent storeys may be required to improve the performance of OGS buildings.

\section{REFERENCES}

[1]. Robin Davis, Devdas Menon And Meher Prasad, "Earthquake-Resistant Design Of Open Ground Storey RC Framed Buildings", Journal Of Structural Engineering, Vol. 37, No. 2, 117-124, June-July 2010.

[2]. Cornell, C. Allin, Fatemeh Jalayer, Ronald O. Hamburger and Douglas A Foutch, (2002) "The Probabilistic Basis For The 2000 SAC/FEMA Steel Moment Frame Guidelines", Journal Of Structural Engineering 128(4), 526-533.

[3]. Monalisa Priyadarshani, Robin Davis P. (2012) Seismic Risk Assessment Of RC Framed Vertically Irregular Buildings. Mtech. Thesis, National Institute Of Technology, Rourkela

[4]. Masanobu Shinozuka, Maria Q. Feng, Ho-Kyung Kim, and Sang-Hoon Kim (2000) "Nonlinear Static Procedure For Fragility Curve Development" Journal Of Engineering Mechanics, Vol. 126, No.12, 1287-1295. 
[5]. Bhagavathula Lohitha, S.V. Narsi Reddy "Earthquake Resistant Design Of Low-Rise Open Ground Storey Framed Building" International Jornal Of Modern Engineering Research (IJMER), Vol. 4, Iss.6, June. 2014.

[6]. Saurabh Singh, Saleem Akhtara And Geeta Bathama "Evaluation Of Seismic Behavior For Multistoried RC Moment Resisting Frame With Open First Storey" International Journal Of Current Engineering And Technology Vol.4, No.1, 01 February 2014.

[7]. Akkar, S., H. Sucuoglu and A. Yakut (2005) "Displacement-based fragility functions for low- and midrise ordinary concrete buildings," Earthquake Spectra, 21(4), 901-927.

[8]. Monalisa Priyadarshini, Robin Davis P, Haran Pragalath D C and Pradip Sarkar. "Seismic Reliability Assessment Of Typical Soft-Storey RC Building In Manipur Region" International Conference on Innovations in Civil Engineering. $9^{\text {th }}$ and $10^{\text {th }}$ May 2013.

[9]. IS 1893 Part 1 (2002) Indian Standard Criteria for Earthquake Resistant Design of Structures, Bureau of Indian Standards, New Delhi.

[10]. IS 456 (2000). "Indian Standard for Plain and Reinforced Concrete" Code of Practice, Bureau of Indian Standards, New Delhi. 2000.

[11]. Standards Institution of Israel (SII). (1995). "Design provisions for earthquake resistance of structures." SI 413, Tel-Aviv, Israel.

\section{BIOGRAPHIES}

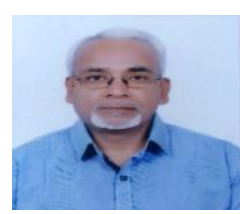

Prof. D.J. Chaudhari, H.O.D. Applied Mechanics Department, Govt. College of Engineering. Amravati.

(Email: dilipbhanu.chaudhari@gmail.com )

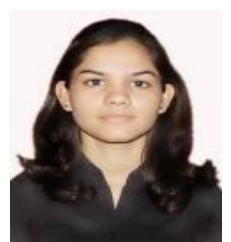

Prajakta T. Raipure, P.G. student, Structural Engineering, Govt. College of Engineering. Amravati.

(Email: praju.raipure@gmail.com) 